\section{8j STRENGTHENING THE CAPACITIES OF HEALTH SYSTEMS FOR DETECTION AND NOTIFICATION OF OCCUPATIONAL DISEASES}

ID Ivanov. World Health Organisation, Geneva, Switzerland

10.1136/oemed-2018-ICOHabstracts.660

Sustainable Development Goal 1 'Eliminating poverty' call for establishing social protection for all, including for victims of occupational diseases and injuries. However the right of victims to access social protection systems, even if they are available, can't be guaranteed if health providers are not able to diagnose and report cases of occupational diseases. Existing research suggest that the barriers for health care providers to report occupational diseases include complex diagnostic and exposure criteria, lack of awareness about occupational diseases, their causes and ways of early detection, lack of time and skills to take detailed occupational history, lack of information on workplace exposures, fear from being involved in legal process, and refusal of workers to have their cases notified. The capacities of health services at all levels for detection and reporting of occupational diseases need to be strengthened by including this task in the terms of reference of primary care and specialised healthcare providers, by providing training, reference resources, and awareness raising campaigns among target groups of health care providers and by establishing referral pathways to specialists in occupational medicine. There is a need for additional research to identify the barriers and to assess the effectiveness of the different measures to encourage detection and reporting of occupational diseases.

\section{WHWB 1 - 'WORKPLACE HEALTH WITHOUT BORDERS - INCREASING IMPACT OF GLOBAL TRAINING AND MENTORING COLLABORATIONS ACROSS ORGANISATIONS: PROTECTING WORKFORCES'}

${ }^{1}$ Claudina MCA Nogueira, ${ }^{2}$ David M Zalk. 'University of Pretoria, Faculty of Health Sciences, Pretoria, South Africa; ${ }^{2}$ International Occupational Hygiene Association (IOHA), Envoy

\subsection{6/oemed-2018-ICOHabstracts.661}

Aim of special session Successful examples of collaborations and WHWB projects for building occupational health and safety capacity will be illustrated, noting how better interactions with other national and international organisations could increase impact. Discussion will focus on how to increase these collaborations and how WHWB can expand its footprint globally, to improve its current offerings in terms of delivering training, mentoring, development and translation of guidance materials, and technical assistance to build knowledge and capacity in occupational health and hygiene, particularly for under-served workforces in both developed and developing countries.

Presenters: ${ }^{1}$ Ms Claudina MCA Nogueira, ${ }^{2} \mathrm{Dr}$ Kevin Hedges, ${ }^{3}$ Dr David F Goldsmith, ${ }^{4}$ Dr Steve M Thygerson

${ }^{1}$ University of Pretoria, Faculty of Health Sciences, Pretoria, South Africa

${ }^{2}$ Occupational Health Clinics for Ontario Workers (OHCOW) Inc., Toronto, Canada

${ }^{3}$ George Washington University, Washington DC, USA

${ }^{4}$ Department of Health Science, Brigham Young University, Provo, Utah, USA

\section{0a 'WORKPLACE HEALTH WITHOUT BORDERS'- BUILDING OCCUPATIONAL HEALTH AND SAFETY CAPACITY THROUGH COLLABORATION WITH UNDER-SERVED POPULATIONS: A GLOBAL PERSPECTIVE}

${ }^{1} \mathrm{CMCA}$ Nogueira*, ${ }^{2} \mathrm{~K}$ Hedges, ${ }^{3} \mathrm{M}$ Levitsky. ${ }^{1}$ University of Pretoria, Faculty of Health Sciences, Pretoria, South Africa; ${ }^{2}$ Occupational Health Clinics for Ontario Workers (OHCOW) Inc., Toronto, Canada; ${ }^{3}$ ECOH Management Inc., Mississauga, Canada

\subsection{6/oemed-2018-ICOHabstracts.662}

Introduction Workplace Health Without Borders (WHWB, www.whwb.org) is an international non-profit organisation founded in 2011 with the main objective of addressing the limited expertise that exists globally for the prevention of workplace disease and injury. Membership is voluntary and comprises professionals across various disciplines within occupational health, the most prominent being occupational hygiene. The WHWB international organisation is based in Canada, with several branches across the world, e.g. WHWBUSA and WHWB-UK.

Methods Through its established and growing network of professionals who volunteer their time and expertise, WHWB is able to offer capacity building in the broad occupational health field, through collaborations that benefit under-served populations and vulnerable workforces across the globe. To date, the WHWB activities have focussed primarily on training, mentoring, development and translation of guidance materials, and technical assistance to build knowledge and capacity in occupational health and hygiene.

Results Gaps and needs in terms of occupational health and hygiene capacity building are identified, mostly in developing countries, through various means. Honouring the requests received involves liaison with organisations associated with the protection of workforces (e.g. government, educational, private enterprises, and tripartite representatives) in the respective countries; the establishment of WHWB in-country projects to best deliver on the type of interventions requested; and the design of good-fit, sustainable programmes that address the needs of the target workforces, across sectors.

Discussion Already in partnerships or working collaborations with organisations such as OHTA and AIHA, WHWB is seeking to expand its collaboration partners, to improve its offerings and footprint in terms of capacity building in occupational health. To this end, opportunities are being explored for partnerships with e.g. ICOH and WHO. This presentation will showcase some of the successes and challenges faced by WHWB intervention projects and training endeavours, and be a platform for discussion around innovative ways for establishing and strengthening collaboration networks.

\section{$1610 \mathrm{~b}$ 'WORKPLACE HEALTH WITHOUT BORDERS' - BUILDING CAPACITY IN THE REDUCTION OF EXPOSURE TO RESPIRABLE CRYSTALLINE SILICA (RCS)}

${ }^{1} \mathrm{~K}$ Hedges ${ }^{*},{ }^{2} \mathrm{M}$ O' Reilly, ${ }^{3} \mathrm{DF}$ Goldsmith, ${ }^{4} \mathrm{O}$ Malik, ${ }^{5} \mathrm{E}$ Cauda. ${ }^{1}$ Occupational Health Clinics for Ontario Workers (OHCOW) Inc., Toronto, Canada; ${ }^{2}$ State University of New York, Albany NY, USA; ${ }^{3}$ George Washington University, Washington DC, USA; ${ }^{4}$ ECOH Management Inc., Mississauga, Canada; ${ }^{5}$ National Institute for Occupational Safety and Health (NIOSH), Greater Pittsburgh, USA

10.1136/oemed-2018-ICOHabstracts.663 